\title{
Modelling and analysis the effect of unbalanced moment directions on behaviour of edge column-slab connections
}

\author{
I Ketut Sudarsana ${ }^{1, *}$, I Gede Gegiranang Wiryadi ${ }^{2}$, and Gede Adi Susila ${ }^{1}$ \\ ${ }^{1}$ Universitas Udayana, Civil Engineering Department, Kampus Bukit Jimbaran-Bali, Indonesia \\ ${ }^{2}$ Graduate Student, Universitas Udayana, Civil Engineering Department, Kampus Bukit Jimbaran, \\ Indonesia
}

\begin{abstract}
This research investigates the effect of unbalanced moment directions on the behaviour of edge column slab connections using a finite element analysis. The analyses were done on subassembly edge column slab connections that were designed according to Indonesian Concrete Standard (SNI 2847:2013). Three unbalanced moment directions were considered namely perpendicular, parallel and inclined $45^{\circ}$ to the slab free edge. The concrete damage plasticity (CDP) and truss elements in Abaqus were utilized to model and analyse the behaviour of concrete and reinforcement bars, respectively. The modelling techniques were first validated using an experimental result available in the literature. There are five parameters in the CDP model need to be validated to get convergent results with the experimental data. Using the CDP validated parameters, then seven specimen models were analysed under combined shear force and an unbalanced moment in three directions. The ratio of $\mathrm{M} / \mathrm{V}$ was kept constant of 0.3 . The results show that the punching failure capacity of connections having an unbalanced moment inclined $45^{\circ}$ is smaller than that of an unbalanced moment perpendicular to the slab free edge, but higher than that of an unbalanced moment parallel to the slab free edge. The patterns of concrete strain are consistent with the moment directions. All tension rebars passing through column sections yield at the connection failures.
\end{abstract}

\section{Introduction}

Punching shear failures around a column is a complex phenomenon. It becomes more complex when unbalanced moment has to be transferred from the slab to the column that cannot be avoided at edge column slab connections. The unbalanced moment can be due to span discontinuity at the slab free edge, or lateral loads caused by earthquake and wind loads. Numerous experimental researches and numerical analysis have been done to investigate the punching failure of the edge column slab connections, however, experimental research needs advanced equipment and quite expensive to investigate a

\footnotetext{
${ }^{*}$ Corresponding author: ksudarsana@unud.ac.id
} 
parameter, therefore, finite element analysis become an alternative solution as done by [1] using finite element based program, Abaqus. It is found that using concrete damage plasticity (CDP) method in Abaqus to model nonlinear behaviour of concrete give the analysis results similar to that of experimental results. A good correlation in deformation, capacity and crack pattern were also found by [2].

Most building codes in the world recommend that in accounting the effect of unbalanced moments due to earthquake load can be taken in parallel direction to building axes, however, it is still worth to investigate the effect of unbalanced moment directions since there are not many data available in the literature. This paper describes the results of finite element analysis on punching behaviour of edge column slab connections due to the effect of shear force and unbalanced moment applied in three different directions. The research investigates the shear capacity, slab deflections, concrete strain as well as tensile stress of the slab reinforcement.

\section{Analysis Method}

A nonlinear analysis using a finite element based software, Abaqus, was conducted on seven specimen models as shown in Table 4 to investigate the effect of the unbalanced moment directions on punching shear phenomena in the edge column slab connections. Nonlinear behaviour of concrete in Abaqus can be modelled using Concrete Damage Plasticity (CDP) Model, which needs to define five parameters namely dilatation angle $(\psi)$, eccentricity $\left(\varepsilon_{\mathrm{c}}\right)$, the ratio of the tensile to the compressive meridian $\left(\mathrm{K}_{\mathrm{c}}\right)$, the ratio between biaxial compressive strength and the uniaxial compressive strength $\left(\sigma_{\mathrm{bo}} / \sigma_{\mathrm{co}}\right)$ and viscosity $(\mu)$. Detail theory of CDP Model can be found in [3,4,5]. The CDP Model has been used previously by $[1,2,6,7,11]$, it was shown that the fifth parameters of CDP model have to be adjusted according the concrete strength.

\subsection{Verification model}

Numerical analysis based on structural dimensions, materials, elements, and other parameters in the CDP model of Abaqus was first verified using an experimental specimen (slab XXX) tested by [8]. Detail process on verification model can be found in [9]. The verification was done iteratively by analysing 22 variation models to seek a correct value of all CDP parameters. It is found that the value of dilatation angle $(\psi)$ of $40^{\circ}$, eccentricity $\left(\varepsilon_{c}\right)$ of $0.1, \mathrm{~K}_{\mathrm{c}}$ of $2 / 3$, the ratio $\left(\sigma_{\mathrm{bo}} / \sigma_{\mathrm{co}}\right)$ of 1.16 , and the viscosity $(\mu)$ of 0.00005 .

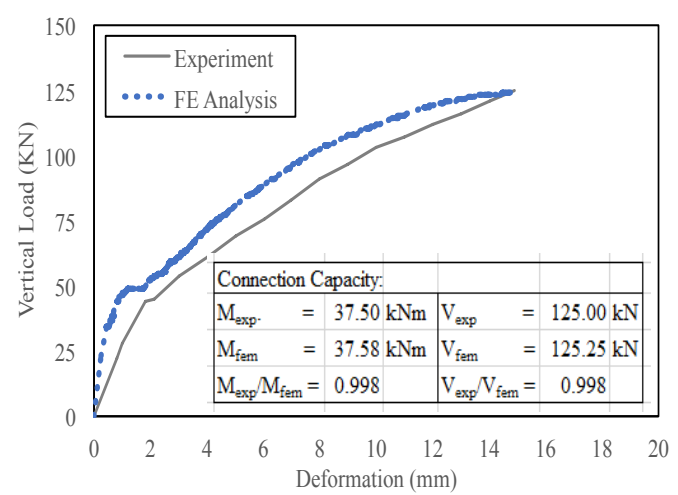

Fig. 1. Experimental and FE analysis deformation of slab XXX.
The mode of failure was based on compression and tension; the tension behaviour of concrete was based on tension strain. The mesh size was 60 $\mathrm{mm}$. The analysis shows that the connection capacities were predicted well with the ratio of experimental to FE analysis $\left(\mathrm{M}_{\text {exp }} / \mathrm{M}_{\text {fem }}\right.$ and $\left.\mathrm{V}_{\text {exp }} / \mathrm{V}_{\text {fem }}\right)$ of 0.998 as shown in Figure 1 . Therefore, the techniques were then used to carry out further analysis in this study. 


\subsection{Specimen models}

The specimen models were subassembly edge column plate connections obtained from a properly designed three storey building having column to column span of 3 meter in both direction following the requirement of [10]. Figure 2 shows the specimen dimensions, reinforcement, and support positions. The specimens were pin supported along three slab edges on the opposite directions of vertical force. All loads were applied through the column stubs. The unbalanced moments were obtained from application of two equal horizontal forces as shown in Figure 2(c). The ratio between a shear force and an unbalanced moment $(\mathrm{M} / \mathrm{V})$ was kept constant of 0.3 with three variations on moment directions namely $0^{\circ}$ (Model E00), 45 (Model E45) and $90^{\circ}$ (Model E90) that are perpendicular, incline $45^{\circ}$ and parallel to slab free edge, respectively. The vertical load (V) and an unbalanced moment $(\mathrm{M})$ were applied simultaneously to keep the aspect ratio of $M / V$ constant up to failure identified.

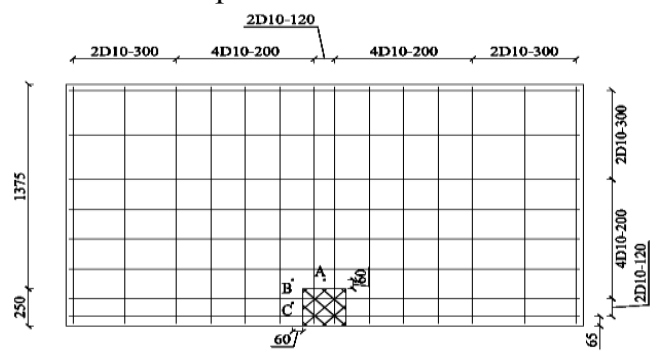

(a) Top slab rebars
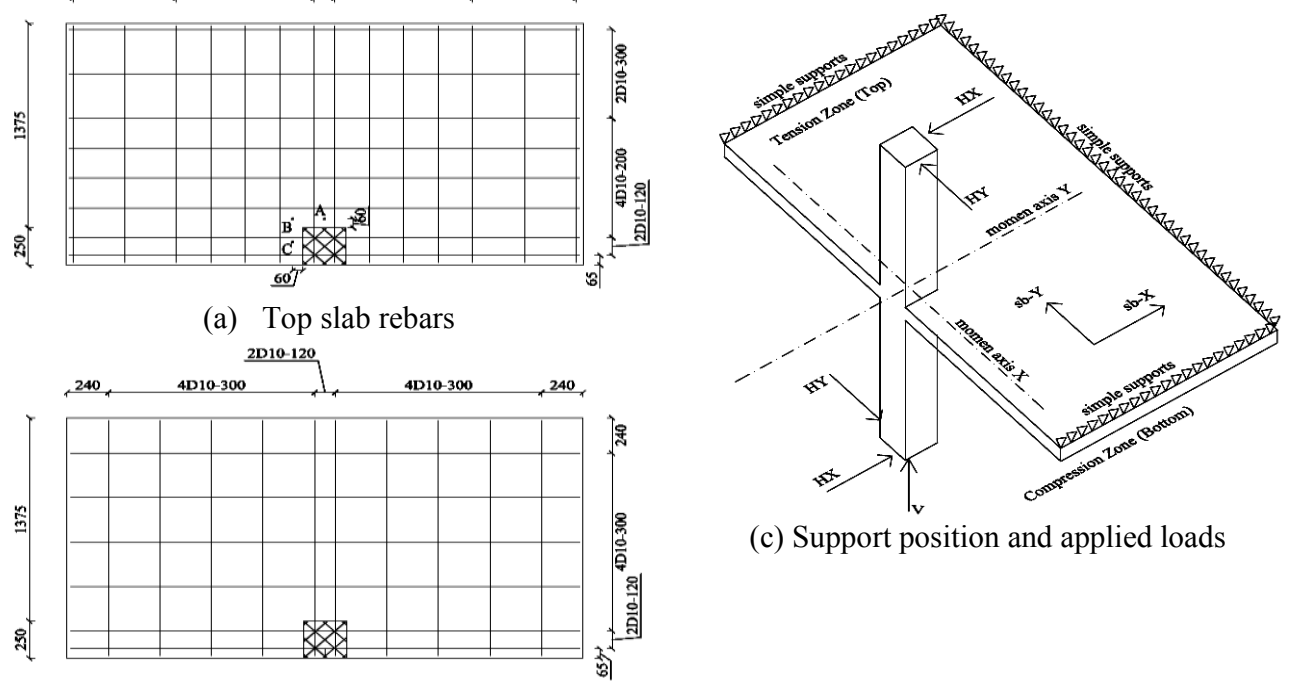

(c) Support position and applied loads

(b) Bottom slab rebars

Fig. 2. Dimension and slab reinforcement of the specimen models. and support position and applied loads

\subsection{Material properties and FE Modelling}

Properties of concrete and reinforcement bars used in the analysis are shown in Table 1. In the absence of test data for stress-strain diagram of concrete, the Hognestad Model (1951) was used. The reinforcement was assumed to be elastoplastic material.

Table 1. Properties of materials.

\begin{tabular}{|l|l|l|l|}
\hline \multicolumn{2}{|c|}{ Concrete properties } & \multicolumn{2}{c|}{ Rebars properties } \\
\hline Compressive strength $\left(\mathrm{f}_{\mathrm{c}}\right), \mathrm{MPa}$ & $: 30$ & Yield stress $\left(\mathrm{f}_{\mathrm{y}}\right), \mathrm{MPa}$ & $: 400$ \\
\hline Tension strength $\left(\mathrm{f}_{\mathrm{ct}}\right), \mathrm{MPa}$ & $: 1.81$ & Ultimate stress $\left(\mathrm{f}_{\mathrm{u}}\right), \mathrm{MPa}$ & $: 600$ \\
\hline Elastic modulus $\left(\mathrm{E}_{\mathrm{c}}\right), \mathrm{MPa}$ & $: 25742$ & Elastic Modulus $\left(\mathrm{E}_{\mathrm{s}}\right), \mathrm{MPa}$ & $: 200000$ \\
\hline $\begin{array}{l}\text { Strain at peak compression stress } \\
\left(\varepsilon_{\mathrm{co}}\right)\end{array}$ & $: 0.0023$ & Yield strain $\left(\varepsilon_{\mathrm{y}}\right)$ & $: 0.002$ \\
\hline Strain at peak tension stress $(\mathrm{et})$ & $: 0.00007$ & Ultimate strain $\left(\varepsilon_{\mathrm{u}}\right), \mathrm{MPa}$ & $: 0.10$ \\
\hline
\end{tabular}


Concrete was modelled using a three-dimension stress element (3D stress) with eight nodes that is defined in Abaqus as C3D8R (8-Node linear brick, reduced integration with hourglass control). These elements were used to reduce the integration for nonlinear analysis. The reinforcement was modelled as a 2-node linear 3-D truss element. According to [11], modelling of reinforcement using one-dimension elements gives equivalent results to model it using solid elements. Concrete and rebars were assumed having a perfect bond that was simulated using embedded region technique in Abaqus.

\section{Results and Discussion}

\subsection{Connections capacity and slab deformation}

Deformations of slab in three locations (A, B, and C) identified in Figure 2(a) are plotted against the vertical loads (V) up to connection failure as shown in Figure 3 together with the model's capacities. It shown that the connection capacity is affected by the unbalanced moment direction. The smallest capacity is obtained when the moment direction parallel to the slab free edge.

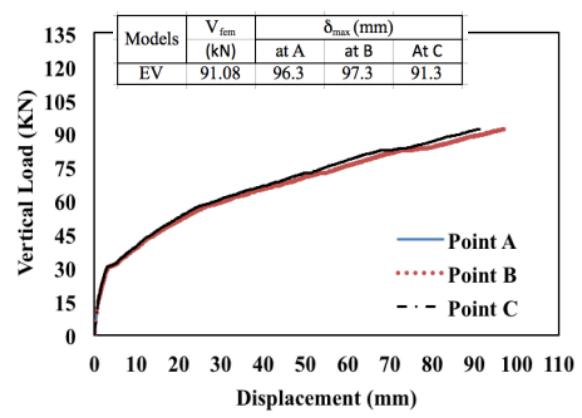

(a) Vertical load only

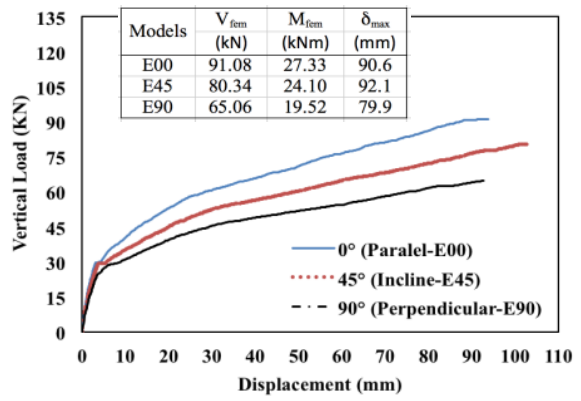

(c) $\mathrm{M} / \mathrm{V}=0.3$ at $\mathrm{B}$

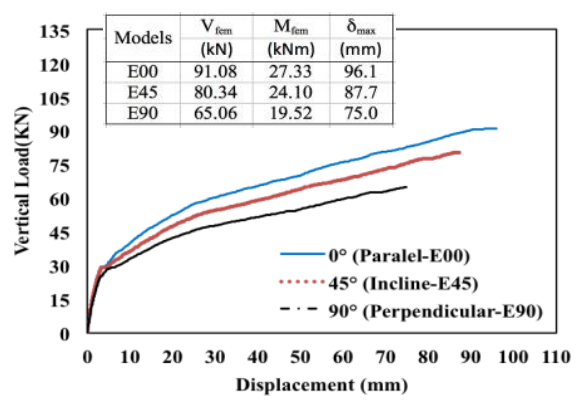

(b) $\mathrm{M} / \mathrm{V}=0.3$ at $\mathrm{A}$

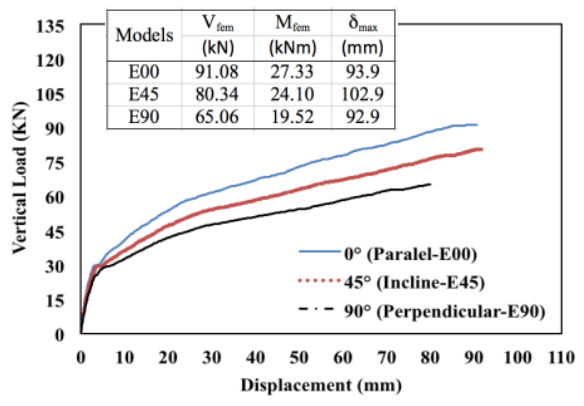

(d) $\mathrm{M} / \mathrm{V}=0.3$ at $\mathrm{C}$

Fig. 3. Vertical load-slab deformation at $60 \mathrm{~mm}$ from the column faces.

\subsection{Concrete strain in slab}

Punching failure of the connections can also be identified base on the strain of the concrete on slab. The slab principle strains are shown in Figure 4. It is shown that the pattern of concrete principal strain follows the moment directions. The highest concrete strain is occurred at the column faces. 


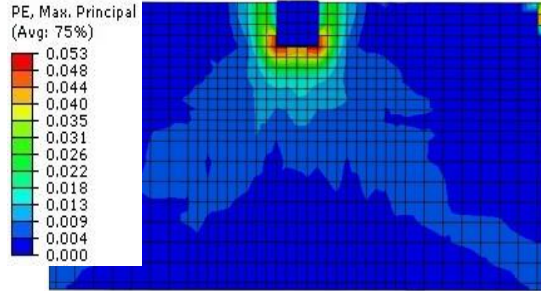

(a). Slab principle strain Model EV

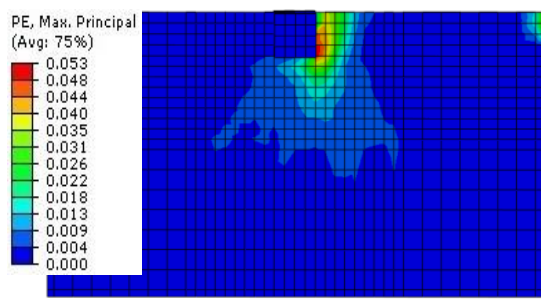

(c). Slab principle strain Model E45

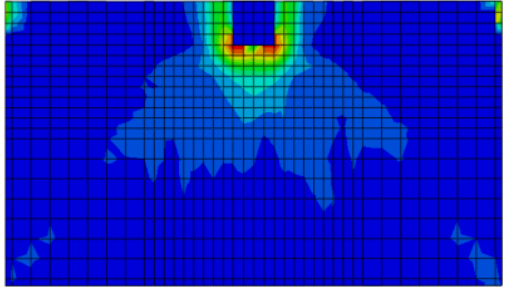

(b). Slab principle strain Model E90

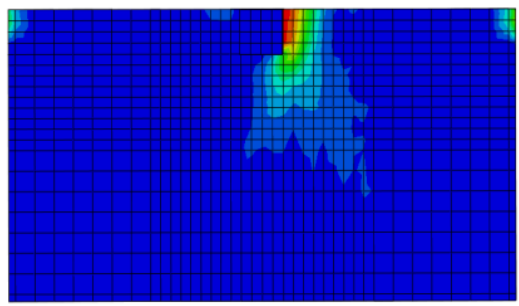

(d). Slab principle strain Model E00

Fig. 4. The concrete principle strain in slab for Model EV, E90, E45 and E00.

\subsection{Rebar stress of slab}

The stress on slab reinforcement was measures at $60 \mathrm{~mm}$ from column faces for both perpendicular and parallel rebars to slab free edge. Figure 5 and 6 provide the tensile stress of the rebars.

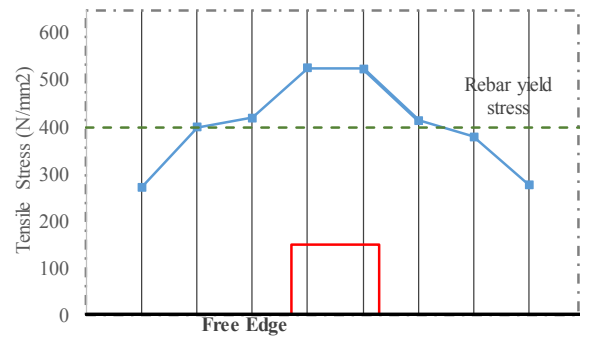

(a) Rebar perpendicular to the slab free edge

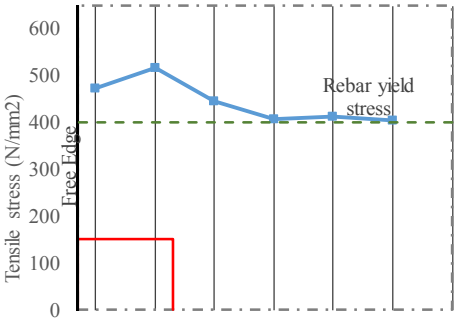

(b) Rebar paralel to the slab free edge

Fig. 5. Stress on tension rebars of the slab on Model EV.

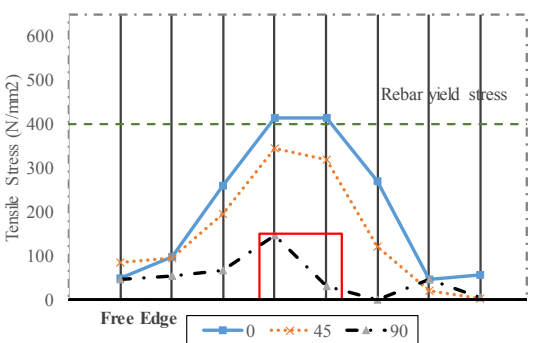

(a) Rebar perpendicular to the slab free edge

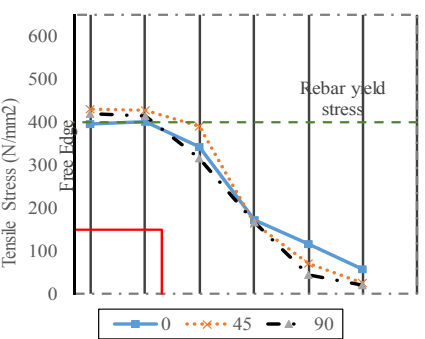

(b) Rebar paralel to the slab free edge

Fig. 6. Stress on tension rebars of the slab in Model E00, E45 and E90.

All tension rebars perpendicular to the slab free edge within the column strip reach yield stress for all loading conditions except for those with unbalanced moment parallel to slab 
free edge. For tension rebars parallel to the slab free edge within the column strips, almost all of them yield at the connection failure except the specimen with pure bending parallel to the slab free edge. This confirms the experimental results obtained by [12] that all rebars passing through the column yield at the punching failure occurred. The tension forces result in from the vertical load and unbalanced moment are resisted dominant by the rebars parallel to the unbalanced moment directions. However, for the connections with the direction of unbalanced moment incline $45^{\circ}$, both parallel and perpendicular rebars to moment direction resist almost equal forces. This indicates that rebars in column strip region contribute punching shear resistance of flat plate as already proposed by [13]. However, this effect has not been adopted in [10] to calculate the punching shear resistance.

\section{Conclusions}

The results of numerical analysis using CDP model in Abaqus shows that the punching capacity of the connections decreases from the moment direction of $0^{\circ}, 45^{\circ}$ and $90^{\circ}$ to the slab free edge. The slab concrete strain and reinforcement tensile stress tend to follow the moment directions. Most of the rebars passing through the edge columns yield at the punching failure. The punching failure capacity of connections having $45^{\circ}$ unbalanced moment is smaller than the connections with unbalanced moment perpendicular to free edge, but higher than the connections with unbalanced moment parallel to the free edge. The patterns of concrete strain are consistent with the moment directions. All tension rebars passing through the column sections yields at the connection failures.

\section{References}

1. A.S. Genikomsou, M.A. Polak, Eng. Str. 98, 38-48 (2015)

2. A.Tambusay, P. Suprobo, Faimun, A. A. Amiruddin, Appl. Mech. and Mat. 851,714719 (2016)

3. ABAQUS, Analysis user's manual 6.14, (Dassault Systems Simulia Corp.,Providence, RI, USA; 2014)

4. J. Lubliner, J. Oliver, S. Oller, E. Oñate, Int. J. Solids Str. 25(3):299-326 (1988).

5. J. Lee, G.L. Fenves, J. Eng. Mech., 124(8), 892-900 (1998).

6. S.V. Chaudhari, M.A. Chakrabarti, Int. J. Comp. Appl. 44(7), 14-18 (2012).

7. Y. Sümer, M. Aktaş, M., J. Str. Mech. 1(3),149-155 (2015).

8. E.F. El-Salakawy, M.A. Polak, M.H. Soliman, Can. J. Civ. Eng. 25, 526-538 (1998).

9. I K. Sudarsana, I G. A. Susila, I G. G. Wiryadi, J. Spektran. 5 (2) 102-111 (2017)

10. SNI 2847:2013. Persyaratan beton struktural untuk bangunan gedung, (BSNI, Jakarta, 2013)

11. T.S.Viswanathan, G.G. Mohan, A.S. Santhi, Int. J. Civ. and Str. Eng. 2,3, (2012).

12.I K.Sudarsana, N.J Gardner, $2^{\text {nd }} A C F$ Conference. (Nusa Dua, Bali-Indonesia, 2006).

13. N.J. Gardner, CSCE J. 23 (2) 502-210 (1996). 